\title{
Perineural Migration of Autologous Stem Cells and Their Role in The Functional Reparation of Injured Internal Organs
}

\author{
Zamaro Alexandra ${ }^{1}$, Koulchitsky Stanislav ${ }^{2}$, Ponomarenko Gennady ${ }^{3}$ and Kulchitsky Vladimir*1 \\ ${ }^{1}$ Brain Center Institute of Physiology, National Academy of Sciences, Minsk, Belarus \\ ${ }^{2}$ Liege University, Liege, Belgium \\ ${ }^{3}$ Federal Scientific Center of Rehabilitation of the Disabled named after GA Albrecht of the Ministry of Labor and Social Protection of the \\ Russian Federation, Saint-Petersburg, Russia
}

*Corresponding author: Kulchitsky Vladimir, Institute of Physiology, National Academy of Sciences, Minsk, Belarus

\section{ARTICLE INFO}

Received: 梆 March 03, 2019

Published: March 15, 2019

Citation: Zamaro Alexandra, Koulchitsky Stanislav, Ponomarenko Gennady, Kulchitsky Vladimir. Perineural Migration of Autologous Stem Cells and Their Role in The Functional Reparation of Injured Internal Organs. Biomed J Sci \& Tech Res 16(1)-2019. BJSTR. MS.ID.002783.

Abbreviations: $\mu \mathrm{m}$ : Micrometer; MSCs: Mesenchymal Stem Cells; PNI: Perineural Invasion; PNMSCs: Perineural Migration Stem Cells; SCs: Stem Cells
ABSTRACT

The problem of the functional reparation of injured internal organs, especially vital ones (heart, lungs) is socially significant, since it has not been solved until now. What body reserves and practical skills of clinicians are the bases for new ideas aimed at preventing and/or restoring impaired functions of internal organs? For the authors of the study, the postulate was the well-known idea that stem cells (SCs) are the foundation for the development of cells during ontogenesis and the implementation of reparative processes in organs and tissues of living organisms. Unfortunately, the endogenous potential of SCs in reality turns out to be insufficient with the development of pathological processes in a living organism. The existing methods of classical therapy, as well as the systemic administration of SCs for the purpose of additional activation of regenerative processes in the body, often turn out to be palliative and insufficient for restoring the working capacity of patients. It is advisable to find new technologies for the activation of reparative processes in the body during the development of pathological processes. The authors propose to supplement the existing technologies for the reparation of the functions of internal organs after their damage with the help of a fundamentally new method of introducing autologous SCs. The technique is based on the natural perineural migration of autologous SCs along the cranial, somatic or autonomic nerves to the site of destruction in the internal organs. As a result, an intensive reparative process is initiated in the damaged tissues. In order to initiate a regenerative process in tissues, a miniature surgery is required under local anesthesia, which is necessary for the perineural administration of autologous SCs. After perineural implantation of SCs, targeted and natural migration of SCs develops to the area of internal organ damage (heart, lungs, liver, pancreas, stomach, spleen, kidneys).

\section{Introduction}

It is paradoxical that the idea of perineural migration stem cell (PNMSCs) usage to initiate reparative processes in humans and animals [1-9] appeared in the article's analysis of the pathological perineural invasion (PNI) mechanisms of cancer cells [10-13]. PNI is typical for various malignant tumors in the process of their manifestation [10-13]. Conditions for the implementation of PNI are pathological changes in the nerve cells and perineural matrix, as well as pathological viability, mobility and invasiveness of tumor cells, initiation of conditions for chemotactic involvement of tumor cells, activation of the adhesion processes of nerve and tumor cells, inhibition of autophagy, apoptosis and immunological surveillance of tumors by cells. The study of the PNI mechanism is important for 
blocking tumor progression and improving patient survival. Recent studies have demonstrated the critical role of nerves in tumor development [13]. The interaction of nerves with cancer cells is typical for various malignant tumors (stomach, pancreas, prostate, and brain cancer). Such a community of cancer and nerve cells is a kind of "black spot" for the patient, since it is accompanied by uncontrolled progress of the tumor process [13].

On the other hand, the development of cellular therapy inspired scientists and clinicians with the hope of improving the efficiency of reparative processes during the development of destructive processes in internal organs and tissues. The authors have gone through all stages of preclinical and clinical observations and officially conduct patient therapy in clinical hospitals of the Republic of Belarus. It is known $[1,5,8,9,14]$ that practically all the internal organs of humans and animals contain stem cells, the reparative potential of which must be learned to use. In the early stages of the work, the authors of the article focused on experimental studies and clinical observations on diseases of the brain and heart [1-9]. Thus, in the heart of humans and mammals, due to the activation of endogenous heart stem cells, significant regeneration of cardiomyocytes is possible $[7,8,14]$. Introduction of autologous stem cells can lead to a significant recovery of the myocardium in heart diseases. The current tactics of clinicians are based on radical technologies, for example, heart transplantation, replacement of the heart in perspective with a portable artificial device, implantation of heart pacemakers, etc. There are objective reasons for choosing such tactics.

The heart of man and mammals is a highly differentiated organ, and so far, it has not been possible to determine the equivalent substitution of a heart transplant in evidence. Clinicians begin to activate the reparative potential of endogenous heart stem cells in the late stages of the development of pathological processes in the heart. Such tactics have little success, are financially costly, and will never cover the entire contingent of heart diseases in need of radical treatment. The axiom that the healing of myocardial infarction occurs through the formation of scar tissue. The progression of pathological myocardial remodeling in patients waiting for help is accompanied by the development of heart failure and sometimes fatal outcome before the start of radical therapy. Unfortunately, there is still an open question whether new scientific discoveries can provide a convincing rationale for extensive clinical trials of stem cell therapy for heart and vascular diseases. The authors of the article chose the method of perineural implantation of SCs for the purposeful migration of SCs to the area of internal organ damage (heart, lungs, liver, pancreas, stomach, spleen, kidneys). This therapy is advisable to carry out at the earliest stages of development of pathological processes in the internal organs.

\section{Central and Peripheral Pathways of Perineural Stem Cell Migration}

Cellular technologies with the use of autologous SCs open up new possibilities for the treatment of socially significant diseases in the early stages of their development. This tactic of treatment is preventive and is aimed at preventing the manifestation of fatal pathological processes. The clinical results of the application of cellular technologies, unfortunately, are not always sufficiently convincing. In this regard, the infusion of stem cells into the bloodstream for diseases of internal organs is still considered experimental and research [14]. The authors of the article focused attention in experiments on animals [1,2,4,6-9] and in observations in clinical conditions $[3,5]$ on the potential of SCs with their perineural administration. In experiments on 3 adult male Wistar rats weighing 200-220g at the time of the experiments have been chosen. All surgery manipulations were performed under ketamine-xylazine-acepromazine anesthesia (55.6, 6.6 and $1.1 \mathrm{mg} /$ $\mathrm{kg}$, respectively, i/p) Figure 1. All rats received 10 thousand SCs in $10 \mu \mathrm{l}$ culture medium in perineural space of vagus nerve at the middle of the neck (Figure 1). SCs were marked with monoclonal antibodies to PKH67 Green Fluorescent Cell Linker. Immediately after the SCs were introduced into the perineural space, laparotomy was performed in the upper abdominal cavity. Gently using an electro coagulator, they touched the surface of one of the three internal organs in each animal: liver, stomach, and pancreas for one second. Figure 1 shows schematically the areas of damaged internal organs. If necessary, hemostasis was performed and then the abdominal cavity was subsequently sutured. All rats were decapitated in one week after surgery and horizontal serial every internal organ slices $8 \mu \mathrm{m}$ in thickness were prepared using Microm HM525 (Germany) cryostat. SCs distribution in damaged internal organs was visualized using Zeiss AxioVert 200M fluorescence microscope with Zeiss AxioCam HRm CCD camera. Figure 2 shows distribution of PKH67 Green Fluorescent Cell Linker labeled SCs in the damaged area of stomach.

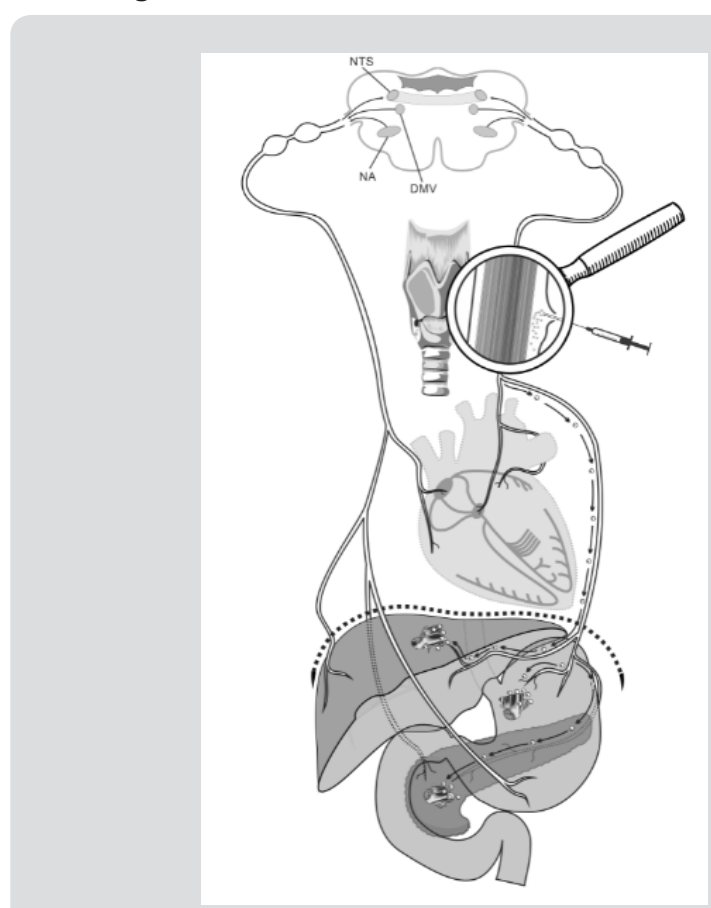

Figure 1: Scheme of perineural implantation of stem cells. 


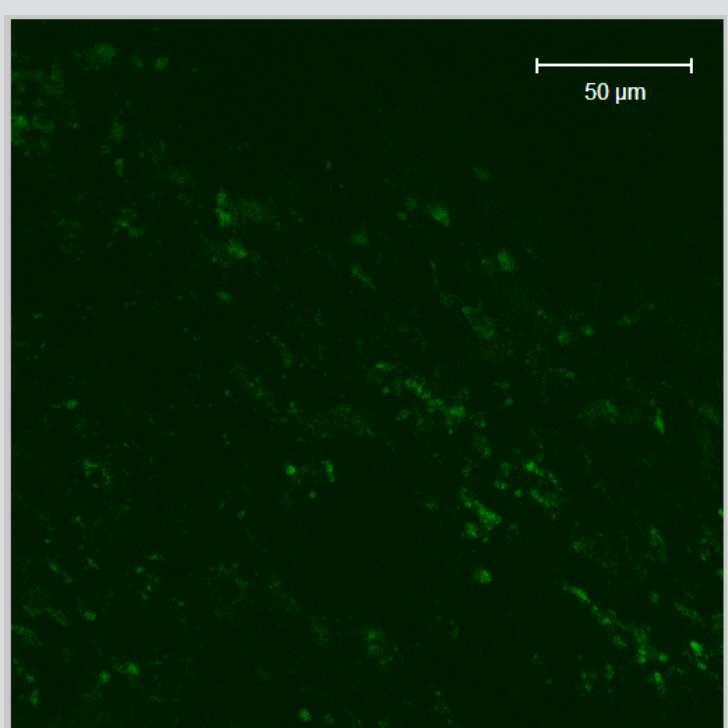

Figure 2: Distribution of PKH67-labeled SCs in the rat

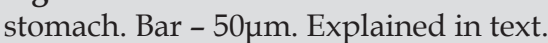

\section{Conclusion}

Conservative therapy of pathological processes in the internal organs is often ineffective. For example, liver cirrhosis is the main cause of death in the development of pathological processes in the liver [15]. The most effective treatment is limited to liver transplantation, which is not available to all patients and is a very expensive method. In this regard, the use of stem cells to regenerate the liver appears to be a promising method $[15,16]$. The data obtained in the treatment of MSCs-conditioned medium confirmed the trophic effects of MSCs, such as increased proliferation and decrease in hepatocyte apoptosis after the activation of several anti-inflammatory and anti-fibrotic cytokines $[15,16]$. In addition to this, attempts have been made to treat patients with cirrhosis with induced pluripotent stem cells [15]. These attempts do not consider the negative side effects of using such cells, the most dangerous of which are teratogenic effects [15]. Most of the procedures for the introduction of SCs were intravenous $[15,16]$, but there are references to the introduction into the hepatic artery [17], as well as the use of systemic application of SCs for cystitis [18], and the possibility of directed movement of SCs using physical factors [19]. The results of the perineural administration of SCs look more promising, especially since in experiments and in clinical conditions the methods of perineural delivery of SCs to different parts of the brain [1-8], as well as to the liver, stomach, pancreas [9], have already been positively tested.

\section{Acknowledgement}

This pooled analysis was funded by 000 "Synergy", and by innovative fund of Brest Regional Executive Committee (20172019), and by BRFFI B18P-227.

\section{References}

1. Kulchitsky V, Zamaro A, Shanko Y, Koulchitsky S (2018) Positive and negative aspects of cell technologies in cerebral diseases. J Neurol Stroke 8(2): 87-88.

2. Kulchitsky V, Zamaro A, Pashkevich S, Sushko T, Koulchitsky S, et al. (2018) Nasolacrimal way of stem cells implantation. J Neurol Stroke 8(2): 110-111.

3. Shanko Y, Navitskaya V, Zamaro A, Zafranskaya M, Krivenko S, et al. (2018) Somatotopic principle of perineural implantation of stem cells in patients with brain injuries. J Neurol Stroke 8(5): 259-261.

4. Shanko Y, Zamaro A, Takalchik Stukach Y, Koulchitsky S, Pashkevich S, et al. (2018) Mechanisms of Neural Network Structures Recovery in Brain Trauma. Biomed J Sci \& Tech Res 7(5): 1-2.

5. Shanko Y, Navitskaya V, Zamaro A, Krivenko S, Zafranskaya M, et al. (2018) Prospects of Perineural Administration of Autologous Mesenchymal Stem Cells of Adipose Tissue in Patients with Cerebral Infarction. Biomed J Sci\&Tech Res 10(1) 1-3.

6. Kulchitsky V, Zamaro A, Shanko Y, Koulchitsky S (2018) Prospects of Perineural Implantation of Stem Cells in Recovery of Neural Networks' Functions in Brain Diseases. Biomed J Sci\&Tech Res 10(3): 1-4.

7. Zamaro A, Koulchitsky S, Pashkevich S, Stukach Y, Dosina M, et al. (2019) Perineural Way of Stem Cells Migration to Injured Heart Regions. Biomed J Sci \& Tech Res 14(1): 1-4.

8. Kulchitsky V, Zamaro A, Koulchitsky S (2019) Perineural Migration of Stem Cells in the Model of Damaged Heart Nodes. Biomed J Sci \& Tech Res 14(4): 1-3.

9. Kulchitsky V, Zamaro A, Krivenchuk D, Koulchitsky S (2019) Can Nerve Trunks Serve as Railroads for Stem Cells? Biomed J Sci \& Tech Res 15(1): $1-4$

10. Azam SH, Pecot CV (2016) Cancer's got nerve: Schwann cells drive perineural invasion. J Clin Invest 126(4): 1242-1244.

11. Chen SH, Zhang BY, Zhou B, Zhu CZ, Sun LQ et al. (2019) Perineural invasion of cancer: a complex crosstalk between cells and molecules in the perineural niche. Am J Cancer Res 9(1): 1-21.

12. Kim JC, Ha YJ, Tak KH, Roh SA, Kwon YH, et al. (2018) Opposite functions of GSN and OAS2 on colorectal cancer metastasis, mediating perineural and lymphovascular invasion, respectively. PLoS One 13(8): e0202856.

13. Deborde S, Wong RJ (2017) How Schwann cells facilitate cancer progression in nerves. Cell Mol Life Sci 74(24): 4405-4420.

14. Sultan S, Kavanagh EP, Michalus R, Hynes N (2018) Stem Cell Smart Technology, where are we now and how far we have to go? Vascular 26(2): 216-228.

15. Kwak KA, Cho HJ, Yang JY, Park YS (2018) Perspectives Regarding Stem Cell-Based Therapy for Liver Cirrhosis. Can J Gastroenterol Hepatol, pp. 4197857.

16. Peng L, Xie DY, Lin BL, Liu J, Zhu HP, et al. (2011) Autologous bone marrow mesenchymal stem cell transplantation in liver failure patients caused by hepatitis B: short-term and long-term outcomes. Hepatology 54(3): 820-828.

17. Berardis S, Sattwika PD, Najimi M, Sokal EM (2015) Use of mesenchymal stem cells to treat liver fibrosis: current situation and future prospects. World J Gastroenterol 21(3): 742-758.

18. Conese M, Beccia E, Castellani S, Di Gioia S, Colombo C, et al. (2018) The long and winding road: stem cells for cystic fibrosis. Expert Opin Biol Ther 18(3): 281-292.

19. Ponomarenko GN (2017) Physical therapy: prospects for the systematic development. Vopr Kurortol Fizioter Lech Fiz Kult 94(6): 59-64. 


\section{ISSN: 2574-1241}

DOI: 10.26717/BJSTR.2019.16.002783

Kulchitsky Vladimir. Biomed J Sci \& Tech Res

(C) (i) This work is licensed under Creative

Submission Link: https://biomedres.us/submit-manuscript.php

$\begin{array}{ll}\text { BIOMEDICAL } & \text { Assets of Publishing with us } \\ \text { RESEARCHES } & \text { - Global archiving of articles } \\ \text { - Immediate, unrestricted online access }\end{array}$

